\title{
The effects of different nitrogen compounds on the growth and microcystin production of Microcystis aeruginosa
}

\author{
Ruihua Dai, Huijuan Liu and Jiuhui Qu
}

\begin{abstract}
The effects of different nitrogen compounds, which include bicine, sodium nitrate, ammonium chloride, glutamic acid and urea, on growth and microcystin (MC) production were studied in batch cultures. The results showed that growth and microcystin production were promoted by bicine, sodium nitrate and ammonium chloride and could not be supported by urea and glutamic acid. It is likely that the cells of Microcystis aeruginosa have no urease which can be utilized to decompose urea. Glutamic acid enters the cell and may interrupt the normal metabolic processes. This would inhibit growth and microcystin production, resulting in the death of the organism. Bicine kept the $\mathrm{pH}$ of the medium at about 8.5 and offered a preferential environment for growth and microcystin production. Ammonium chloride could be utilized by Microcystis aeruginosa indirectly. During the process of assimilation, hydroxy ions were continuously consumed, which would lead to a reduction in $\mathrm{pH}$ to less than 7 and retard growth and microcystin production. In the presence of sodium nitrate, the metabolic and biochemical mechanisms, which use sodium nitrate as a source of nutrition during the process of expanding vaccination, were impossible to change in a short time. Thus, sodium nitrate promoted growth and microcystin production.

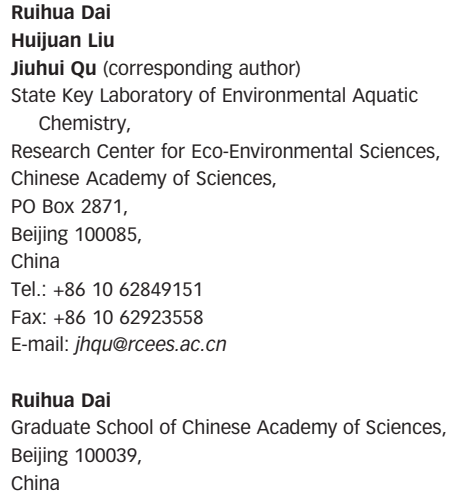

Key words I growth, microcystin production, Microcystis aeruginosa, nitrogen compounds

\section{$\overline{\text { INTRODUCTION }}$}

The eutrophication of lakes, ponds and reservoirs is caused by an increase in nitrogen and phosphorus, leading to the occurrence of harmful cyanobacterial blooms, which are becoming a serious environmental problem worldwide. Microcystins (MCs) are produced by various cyanobacteria such as Microcystis, Anabaena, Oscillatoria and Nostoc species, which inhibit eukaryotic protein phosphatases and cause excessive phosphorylation of cytoskeletal filaments and liver failure of animals. Among the toxic cyanobacteria, Microcystis aeruginosa ( $M$. aeruginosa) is commonly observed in highly eutrophic lakes (Watanabe \& Oishi 1985). The MCs produced by M. aeruginosa have been the cause of several poisonings of domestic animals and wildlife around the world, and they also pose a health hazard for doi: 10.2166/aqua.2009.032 humans through the use of water for drinking and recreation (Hoeger et al. 2007). Understanding the conditions of MC production by harmful cyanobacterial blooms is of fundamental significance for the control of this environmental problem.

It is well known that nitrogen is not only a main nutrient for cyanobacterial growth but also a key element in the composition of MCs. Furthermore, nitrogen accounts for over $14 \%$ of the molecular weight of microcystin-LR (MC-LR). Therefore, many scientists have focused on the effects of nitrogen, especially dissolved inorganic nitrogen (DIN) on MC production using the M. aeruginosa species (Vezie et al. 2002; Downing et al. 2005; Amé \& Wunderlin 2005). However, various nitrogenous forms occur in 
eutrophic water (Flynn \& Butler 1986). Among these nitrogenous forms, urea is ubiquitous in eutrophic water (Berman 1974; Berman et al. I999) and has been demonstrated to provide nitrogen for phytoplankton by many researchers around the world (Berman I997; Berman et al. I999; Glibert \& Terlizzi I999). Amino acids are available forms of dissolved organic nitrogen (DON) in water (Gardner \& Lee 1973; Ittekkot 1988), of which glutamic acid, glycine, alanine and aspartic acid are most abundant (Lytle \& Perdue I98I; Ittekkot I982; Rosa \& Nunes 2005; Duan \& Bianchi 2007; Gors et al. 2007). When the concentration of DIN is low or depleted, urea and amino acids may provide a significant source of available nitrogen for $M$. aeruginosa. Comparative studies on MC production by $M$. aeruginosa have been limited to investigate the effects of inorganic nitrogen. The roles of dissolved organic nitrogen on the growth and production of MC have not been paid much attention.

MC-LR is the most commonly found toxin among many cyanobacterial blooms worldwide (Rinta-Kanto et al. 2005) and is one of the most toxic microcystins with an LD50 $\mu \mathrm{g} \mathrm{kg}^{-1}$ of 50 in mice (Rinehart et al. I994). In the present study, a strain of $M$. aeruginosa, the toxin of which was mainly MC-LR, was studied. The effects of different nitrogen compounds on growth and production of MC-LR were investigated. Results indicated that chemical forms of bicine, nitrate and ammonium played important roles in promoting the growth and production of MC-LR by cyanobacteria, which may be important for understanding and practical control of harmful cyanobacterial blooms.

\section{MATERIALS AND METHOD}

\section{M. aeruginosa}

An axenic strain of $M$. aeruginosa, which was isolated from Dianchi Lake in China, was obtained from Institute of Hydrobiology, Chinese Academy of Science.

\section{Culture medium and culture conditions}

M. aeruginosa was maintained in BG11 medium (Table 1). Initial $\mathrm{pH}$ of the medium was adjusted to 8.5 using $1.0 \mathrm{moll}^{-1}$ hydrochloric acid and sodium hydroxide solutions. The medium and all experimental utensils were kept at $121^{\circ} \mathrm{C}$ for $20 \mathrm{~min}$ in order to sterilize the bacteria. Cultures in exponential phase were concentrated by centrifugation and washed three times with sterile distilled water and then inoculated in the same growth medium, but without a nitrogen source for a week to exhaust the nitrogen in the cells. The $M$. aeruginosa were then added to a series of 2.5-1 flat-bottomed bottles which contained 21 medium and were supplemented with $250 \mathrm{mgl}^{-1}$ of one of the following nitrogen compounds: bicine, sodium nitrate, ammonium chloride, glutamic acid and urea. Control bottles were incubated with the same algal inocula without nitrogen medium.

Table 1 | Composition of BG11 medium for Microcystis aeruginosa*

\begin{tabular}{|c|c|c|c|}
\hline Nutrients & Concentration $\left(\mathrm{gl}^{-1}\right)$ & Trace metal mix $\mathbf{A}_{5}$ & \\
\hline $\mathrm{NaNO}_{3}$ & 1.500 & $\mathrm{H}_{3} \mathrm{BO}_{3}$ & $2.86 \mathrm{~g}$ \\
\hline $\mathrm{K}_{2} \mathrm{HPO}_{4}$ & 0.04 & $\mathrm{MnCl}_{2} \cdot 4 \mathrm{H}_{2} \mathrm{O}$ & $1.81 \mathrm{~g}$ \\
\hline $\mathrm{MgSO}_{4} \cdot 7 \mathrm{H}_{2} \mathrm{O}$ & 0.075 & $\mathrm{ZnSO}_{4} \cdot 7 \mathrm{H}_{2} \mathrm{O}$ & $0.222 \mathrm{~g}$ \\
\hline $\mathrm{CaCl}_{2} \cdot \mathrm{H}_{2} \mathrm{O}$ & 0.036 & $\mathrm{CuSO}_{4} \cdot 5 \mathrm{H}_{2} \mathrm{O}$ & $0.079 \mathrm{~g}$ \\
\hline Citric acid & 0.006 & $\mathrm{NaMoO}_{4} \cdot 2 \mathrm{H}_{2} \mathrm{O}$ & $0.390 \mathrm{~g}$ \\
\hline Ferric ammonium & 0.006 & $\mathrm{Co}\left(\mathrm{NO}_{3}\right) \cdot 6 \mathrm{H}_{2} \mathrm{O}$ & $0.049 \mathrm{~g}$ \\
\hline EDTA (dinatrium salt) & 0.001 & Distilled water & $1,000 \mathrm{ml}$ \\
\hline $\mathrm{NaCO}_{3}$ & 0.02 & & \\
\hline Trace metal mix $A_{5}$ & $1.0 \mathrm{ml}$ & & \\
\hline Distilled water & $919 \mathrm{ml}$ & & \\
\hline
\end{tabular}

*pH should be about 8.5 after sterilization. 
All samples were run in triplicate bottles at $26^{\circ} \mathrm{C}$ and a light intensity of $400 \sim 650 \mathrm{~lx}$ with a $12 \mathrm{~h}$ photoperiod. All flat-bottomed bottles were shaken by hand three times every day during the maintenance and experimental stages. Sub-samples were taken at predetermined intervals after inoculation during the incubation period to count the cell number and extract the MC.

\section{Measurement of cell number}

After straining with Lugol's iodine solution, the population of $M$. aeruginosa cells was twice counted under a microscope using a haemocytometer. Cell counts were performed to a minimum precision of $20 \%$, or a third cell count was needed. At the same time, the medium was inspected to ascertain whether $M$. aeruginosa had been contaminated by extraneous bacteria.

\section{Determination of MC within the cells}

After inoculation, a $50 \mathrm{ml}$ sample of cyanobacterial culture solution was taken at two-day intervals. The samples were centrifuged at $8,000 \mathrm{rmin}^{-1}$ for $10 \mathrm{~min}$ and then the supernatant was discarded. The cell pellet was frozen at $-20^{\circ} \mathrm{C}$ for over $24 \mathrm{~h}$, then $20 \mathrm{ml} 50 \%$ methanol-water solution was added to the cell pellet to extract MC within the cyanobacterial cells. The extraction solution was crushed using an Ultrasonic Cell Disruptor (JY92-2D, SCIENTZ, China) for $30 \mathrm{~min}$ and then was put in boiling water for $20 \mathrm{~min}$ to extract MC. The solution was centrifuged at $8,000 \mathrm{r} \mathrm{min}^{-1}$ for $10 \mathrm{~min}$ and the supernatant was filtered through $0.22 \mu \mathrm{m}$ membranes. The filtration was enriched to $1 \mathrm{ml}$ by mild nitrogen gas with a nitrogen evaporator (KL512, Kanglin Co., China) and measured for MC on HPLC. The MC content in the cells was calculated from the ratio of the concentration of $\mathrm{MC}$ in the extraction solution $\left(\mathrm{mgl}^{-1}\right)$ to the cells in the sub-samples (cells $\mathrm{ml}^{-1}$ ). The data presented here were the average values of three parallel samples with standard deviation.

Standard MC-RR and MC-LR bought from Sigma (98\% purity) and samples of MC-RR and MC-LR were analysed by HPLC (Hitachi L-2000) with a reverse ZORBAX SB-C18 column $(4.6 \mathrm{~mm} \times 250 \mathrm{~mm}$, Agilent Co., USA) and a diode array detector at $238 \mathrm{~nm}$. The mobile phase was 35\% (v/v) acetonitrile-water solution containing 0.05\% $(\mathrm{v} / \mathrm{v})$ of frozen acetic acid. The flow rate was $1.0 \mathrm{ml} \mathrm{min}^{-1}$ and the injection amount was $20 \mu l$.

\section{RESULTS}

\section{Analysis of MC-RR and MC-LR}

Microcystins were identified by their characteristic absorption spectra $(238 \mathrm{~nm})$ and retention times and quantified by HPLC analysis. Figure 1(a) shows the HPLC profile of standard solution of $5 \mathrm{mgl}^{-1}$ of MC-RR and MC-LR. Peaks of MC-RR and MC-LR appeared at 4.33 and $6.76 \mathrm{~min}$, respectively. The wavelength of $238 \mathrm{~nm}$ was the maximum absorbance of MC-RR and MC-LR, which agreed with the literature (Moollan et al. 1996) and was used for the detection of MC on HPLC in this experiment. Good linear relationships between the peak area and the standard concentrations of MC-RR and MC-LR were obtained at a wavelength of $238 \mathrm{~nm}\left(R^{2}=0.998\right.$ and 0.999). Figure 1(b) shows the HPLC profile of MC in the cells of M. aeruginosa. It can be observed that the MC in the cells was MC-LR and that the M. aeruginosa produced MC-LR but no MC-RR.

\section{Extraction of MC}

The extraction of MC from the cells of M. aeruginosa was investigated by using different concentrations of methanol solution containing 100\% methanol, $80 \%$ methanol, 50\% methanol, $10 \%$ methanol and 100\% water. Figure 2 indicates that the extraction efficiency of MC-LR within cells using $50 \%$ methanol was slightly higher than those using other methanol solutions and that of using 100\% methanol was worst. Lawton \& Edwards (200I) recommended 50-80\% methanol as the optimal extraction solution. In the present study, 50\% methanol was used to extract MC.

\section{The effects of different nitrogen compounds on growth of $M$. aeruginosa}

In natural water, all kinds of nitrogenous compound exist at the same time. M. aeruginosa might assimilate these compounds as nitrogen sources to support its growth. As shown in Figure 3, different nitrogen compounds had 


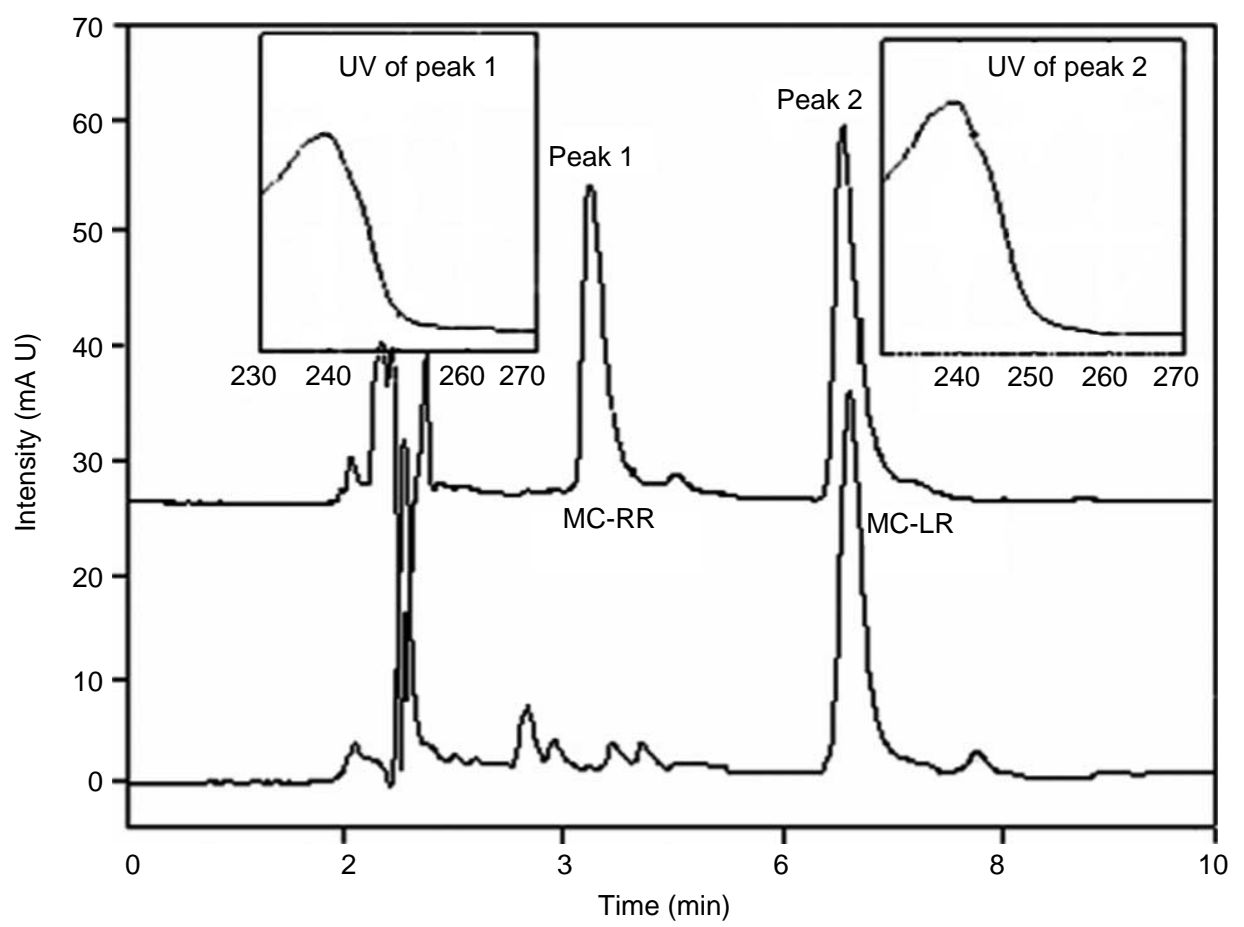

Figure 1 The HPLC profiles for (a) standard MC-RR (RT $=4.33 \mathrm{~min}$ ) and MC-LR (RT $=6.76 \mathrm{~min})$ and (b) the profiles for MC-LR in the cells of Microcystis aeruginosa. Concentrations of standard MC-RR and LR are $5 \mathrm{mgl}^{-1}$, respectively.

different effects on the growth of $M$. aeruginosa. It was shown that $M$. aeruginosa could grow well in a medium containing sodium nitrate, bicine and ammonium chloride, respectively, but could not grow in urea. However, in the presence of glutamic acid, $M$. aeruginosa grew faster than with other nitrogen compounds until $96 \mathrm{~h}$ and then became

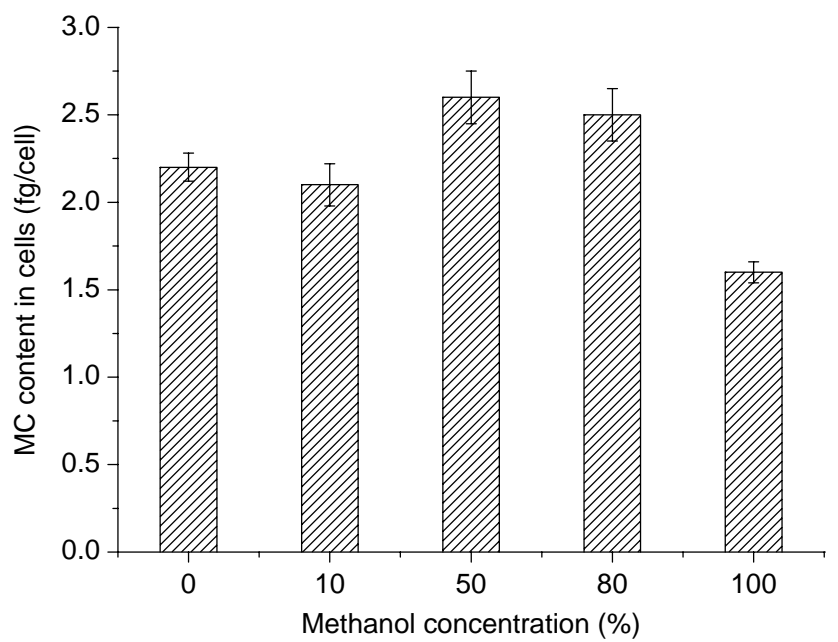

Figure 2 | Extraction of MC-LR from Microcystis aeruginosa using different concentrations of methanol. yellow. Figure 3 indicates that the growth of $M$. aeruginosa in the medium containing sodium nitrate, bicine and ammonium chloride reached exponential phases on the fifth day and late-exponential phases on the 14th day and their growth was a typical example of batch culture growth. Cells of M. aeruginosa grown on bicine, sodium nitrate and

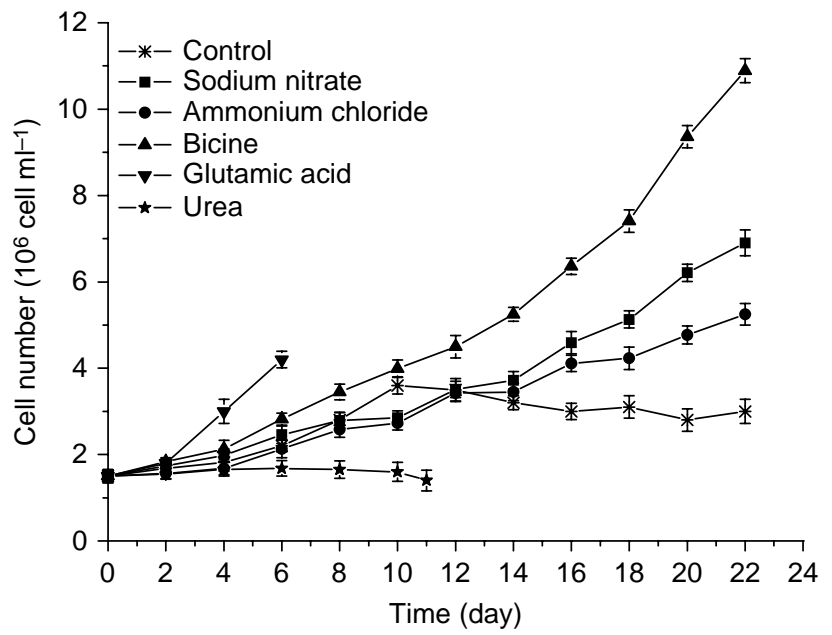

Figure 3 Effects of different nitrogen compounds on the growth of Microcystis aeruginosa. 
ammonium chloride attained maximum cell numbers of $10.89 \times 10^{6}, 6.90 \times 10^{6}$ and $5.25 \times 10^{6}$ cells ml $^{-1}$, respectively. Correspondingly, in the presence of glutamic acid, the maximum cell number was up to $3.00 \times 10^{6}$ cells ml $^{-1}$ at $96 \mathrm{~h}$ and exceeded the cell number with bicine. However, growth ceased after $96 \mathrm{~h}$ and the appearance of the culture became yellow and turbid.

According to these results, the order of growth promotion of the five different nitrogen compounds was as follows: bicine $>$ sodium nitrate $>$ ammonium chloride $>$ glutamic acid $>$ urea.

\section{The effects of different nitrogen compounds on MC production of $M$. aeruginosa}

This study has demonstrated that $M$. aeruginosa can take up bicine, sodium nitrate and ammonium chloride to support its growth, but cannot utilize glutamic acid and urea. However, whether those nitrogen compounds could promote microcystin production was more important. Figure 4 shows the microcystin content with different compounds as the nitrogen source. It is noticeable that the MC content in the presence of bicine, sodium nitrate and ammonium chloride gradually increased up to a maximum on the 10th day from the late-lag phase to the exponential phase; moreover, the MC content declined in the lateexponential phase as shown in Figure 4. This result agreed with the literature (Yan et al. 2004; Amé \& Wunderlin 2005). Figure 4 also shows that bicine promoted higher

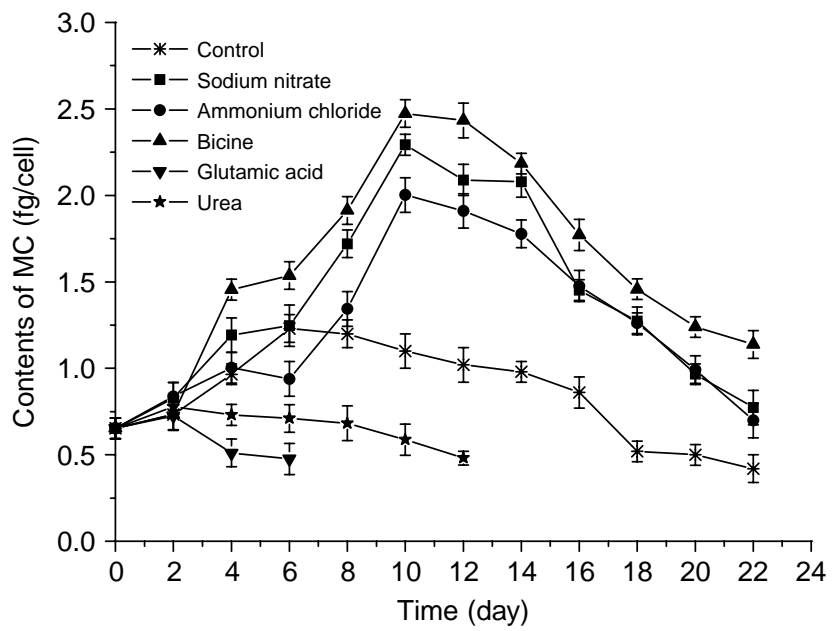

Figure 4 | Effects of different nitrogen compounds on MC production of Microcystis aeruginosa. production of MC-LR than sodium nitrate and ammonium chloride. The maximum content of MC-LR in bicine reached 2.47 femtogram/cell (fg/cell) on the 10th day. The MC production of sodium nitrate and ammonium chloride ranked in second and third place with $2.29 \mathrm{fg} / \mathrm{cell}$ and $2.00 \mathrm{fg} /$ cell, respectively.

As shown in Figure 4, glutamic acid did not promote the production of MC-LR. Here, maximum MC production was $0.73 \mathrm{fg} /$ cell, lower than that of the control $(1.1 \mathrm{fg} / \mathrm{cell})$. The medium containing urea did not increase the production of MC-LR (Figure 4). Its MC production was always lower than that of the control throughout the batch experiments.

Figure 4 shows that the order of nitrogen compounds in terms of their effect on MC production was as follows: bicine $>$ sodium nitrate $>$ ammonium chloride $>$ urea $>$ glutamic acid; similar to that of growth. Our results for the contrasting roles of the five compounds tested in the promotion of growth and the promotion of MC-LR production indicated that the MC production was correlated to the growth of the cyanobacterium.

\section{$\overline{\text { DISCUSSION }}$}

Cyanobacterial toxin production has been reported to be affected by various environmental factors of which the physical, chemical and biological parameters are most often investigated. We, therefore, focused our study on the effect of different nitrogen compounds on growth and microcystin production in $M$. aeruginosa, one of the bloom-forming toxic cyanobacteria isolated from Dianchi Lake, southwestern China. Our results showed that microcystin-LR was the major toxin in this strain and 50\% methanol had better extraction efficiency. The present study also clearly demonstrated that bicine, sodium nitrate and ammonium chloride could be used as the sole nitrogen source to support the growth of $M$. aeruginosa and promote MC production. M. aeruginosa could not utilize glutamic acid and urea to support natural and sustaining growth or to stimulate MC production.

Growth and MC production were both inhibited by urea, which may be attributed to the lack of urease in the cells of $M$. aeruginosa. Urease is the key determinant of 
whether the phytoplankton can use urea as a nitrogen source (Amé \& Wunderlin 2005). This demonstrated that urea, which is imported into natural water by human activity, does not directly stimulate the growth of $M$. aeruginosa; on the contrary, it could inhibit the growth. However, due to the complexity of the natural water, urea is probably decomposed to ammonia by bacteria and microorganisms, leading to the outbreak of the cyanobacterial bloom. It has been reported that cyanobacteria Microcystis and Synechococcus could grow well with urea as a nitrogen source (Berman \& Chava 1999). However, that experiment was not operated in axenic conditions. Urea was converted into other nitrogen sources by bacteria in the medium. In this condition, the nitrogen source that was utilized by M. aeruginosa was not urea. Therefore, the results of the Berman \& Chava (I999) study were in opposition to our results.

Glutamic acid was not utilized as a nitrogen source to support the growth of $M$. aeruginosa, although biomass of M. aeruginosa was quickly promoted in the first four days. But the promotion was unusual. It has been reported that glutamic acid is crucial in the processes of amino acid uptake, metabolism and transformation within the algal cells, and leucine, tryptophan, valine and aspartic acid were transformed through the metabolism of glutamic acid. In normal algal cells, the concentration of glutamic acid lies within a certain range. When $M$. aeruginosa was poured into the medium containing glutamic acid, it took up a small amount of glutamic acid and its growth was rapidly promoted at the beginning of incubation. However, with substantial absorption of glutamic acid, excessive amounts accumulated in the cells and exceeded the normal range, leading to the destruction of the normal amino acid cycle and influencing the normal physiological process of metabolism. Therefore, M. aeruginosa rapidly became yellow and died.

The $\mathrm{pH}$ value was also an important factor for growth and $\mathrm{MC}$ production. The present study measured the $\mathrm{pH}$ of the medium in the presence of bicine, sodium nitrate and ammonium chloride. As shown in Figure 5, during the process of incubation, the $\mathrm{pH}$ of the medium containing bicine was in the range $8.2 \sim 8.5$, with sodium nitrate the $\mathrm{pH}$ was between 8.5 and 9.5, and with ammonium chloride the $\mathrm{pH}$ was below 7 .

A suitable $\mathrm{pH}$ for the growth of M. aeruginosa is about 8.5 , and acidic conditions are detrimental to growth. It has

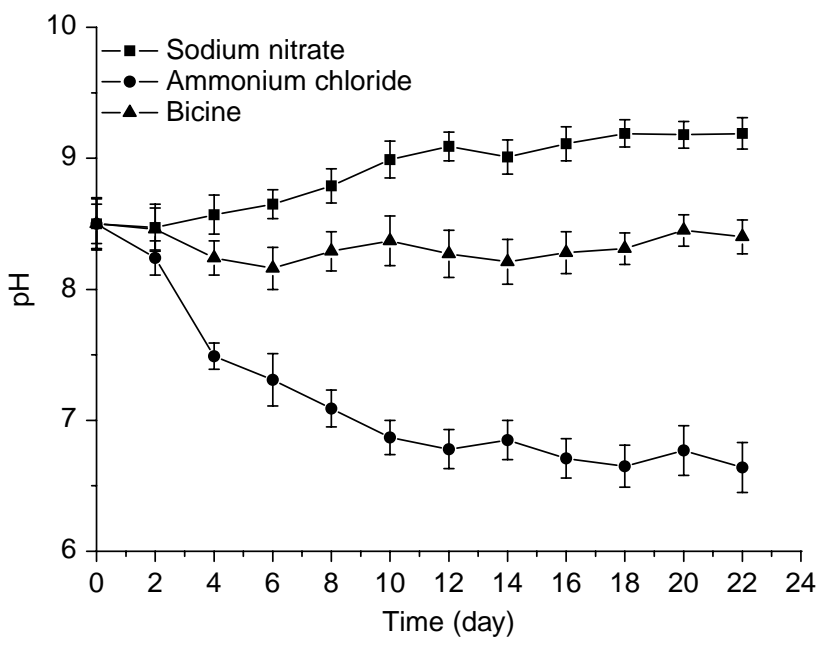

Figure $\mathbf{5} \mid \mathrm{pH}$ value of the medium in the presence of sodium nitrate, ammonium chloride and bicine.

been reported that algae can directly absorb $\mathrm{NH}_{4}^{+}$when ammonium chloride exists in the medium. However, ammonium is vulnerable to entering into the cells with the non-dissociation of ammonium hydroxide (Liu 1999), as shown in Equation (1).

$\mathrm{NH}_{4}^{+}+\mathrm{OH}^{-}=\mathrm{NH}_{4} \mathrm{OH}$

The hydroxy ion is continuously consumed in this process, which causes the $\mathrm{pH}$ of the medium to decrease. Moreover, $\mathrm{pH}$ was lower with a higher concentration of ammonium chloride in the medium. It was possible that $\mathrm{pH}$, which declined during the growth of algae, inhibited the growth of $M$. aeruginosa. In the present study, the concentration of ammonium chloride was $250 \mathrm{mgl}^{-1}$ Therefore, the growth and MC production was obviously inhibited. Although it has been reported that MC content would be promoted at lower $\mathrm{pH}(<7)$ (Amé \& Wunderlin 2005), the growth and MC content were largely influenced by low $\mathrm{pH}$. The inhibitory action was greater than the promoting action.

Before nitrate nitrogen is assimilated to synthesize protein and other metabolites as raw materials, it must be first transformed into ammonia (Liu I999). The four steps are shown in the following Equations (2)-(5).

$\mathrm{NO}_{3}^{-}+2 \mathrm{H}^{+}+2 e \rightarrow \mathrm{NO}^{2-}+\mathrm{H}_{2} \mathrm{O}$ 
$2 \mathrm{NO}_{2}^{-}+4 \mathrm{H}^{+}+4 e \rightarrow \mathrm{N}_{2} \mathrm{O}_{2}^{2-}+2 \mathrm{H}_{2} \mathrm{O}$

$\mathrm{N}_{2} \mathrm{O}_{2}^{2-}+6 \mathrm{H}^{+}+6 e \rightarrow 2 \mathrm{NH}_{2} \mathrm{OH}$

$\mathrm{NH}_{2} \mathrm{OH}+2 \mathrm{H}^{+}+2 e \rightarrow \mathrm{NH}_{3}+\mathrm{H}_{2} \mathrm{O}$

Hydrogen ions are continuously consumed during the process of reduction, which increases the $\mathrm{pH}$ causing the medium to become alkaline. In the present study, the $\mathrm{pH}$ of the medium was up to about 9.5, and high $\mathrm{pH}$ would affect the growth of $M$. aeruginosa. However, the $M$. aeruginosa was cultured in the medium containing nitrate during the process of expanding vaccination. Although the nitrogen compounds within the cells were depleted through the process of pre-incubation, the metabolic and biochemical mechanisms, which use sodium nitrate as a source of nutrition, were impossible to change in such a short time. Therefore, nitrate promoted growth and MC production.

Bicine, chemical name N,N-dihydroxyethyl glycine, is a ramification of glycine. Furthermore, it is a buffer and is often used as a biological buffer because the molecule contains two hydroxyls. In this study, bicine was not only a nitrogen source, but also played the role of buffer. The $\mathrm{pH}$ of the medium remained at about 8.5 , which provided a good growth environment for $M$. aeruginosa and thus promoted the greatest degree of growth and MC production. The bicine supported more rapid growth and a higher content of MC-LR within the cells of M. aeruginosa, which is in agreement with the findings that the production of MC was controlled by environmental effects on the rate of cell division of $M$. aeruginosa (Orr \& Jones I998).

Rao et al. (1996) found that MA medium containing bicine and nitrate as nitrogen sources supported the best growth of $M$. aeruginosa among the five media tested. Our results confirmed that the nitrogen chemicals of bicine, nitrate and ammonia were important in the rapid growth and MC production of $M$. aeruginosa. They are good nitrogen sources for $M$. aeruginosa. Therefore, they can stimulate the cyanobacterial bloom with a high content of MC. Bicine, an amino acid, promoted the greatest growth and MC production among the tested nitrogen compounds. This demonstrated that amino acids are directly involved in the metabolism of algae and even promoted its growth and toxin production. Normal physiological metabolism of this cyanobacterium might be disrupted by glutamic acid, which was responsible for the severe inhibition of growth and MC production. This phenomenon requires further study.

The data reported here constitute a basis for investigation into the different nitrogen compounds that correlate with increased MC production rates and suggest that amino acid assimilation in natural water may be involved in the regulation of MC production. Such information might shed light on the nature of the mechanism of up-modulation of MC.

\section{CONCLUSIONS}

(1) Bicine, sodium nitrate and ammonium chloride promoted growth and microcystin production to different degrees. Urea could not support growth and microcystin production. Although cell division was accelerated by glutamic acid at the beginning of the incubation period, growth and microcystin production was not supported.

(2) It is likely that the cells of $M$. aeruginosa do not contain urease which can be utilized to decompose urea. Therefore, urea was not used as a nitrogen source by $M$. aeruginosa. Glutamic acid enters the cells of $M$. aeruginosa and might interrupt the normal metabolic processes. This would inhibit growth and microcystin production, and cause the death of the organism.

(3) Bicine, which is a buffer solution, kept the $\mathrm{pH}$ of the medium at about 8.5 and offered a preferential environment for growth and microcystin production. Ammonium chloride could be utilized by $M$. aeruginosa indirectly. During the process of assimilation, hydroxy ions were continuously consumed, which would cause the $\mathrm{pH}$ to drop to less than 7 , retarding growth and microcystin production.

(4) After sodium nitrate is transformed to ammonia, it can be utilized by $M$. aeruginosa. Hydrogen ions are consumed in the process and result in increased $\mathrm{pH}$. However, the metabolic and biochemical mechanisms, which use sodium nitrate as a source of nutrition during the process of expanding vaccination, were 
impossible to change in such a short time. Thus, sodium nitrate promoted growth and microcystin production.

\section{ACKNOWLEDGEMENTS}

This work is supported by the National Basic Research Program of China (Grant No.: 2007CB407301).

\section{REFERENCES}

Amé, M. V. \& Wunderlin, D. A. 2005 Effects of iron, ammonium and temperatures on microcystin content by a natural concentrated Microcystis aeruginosa population. Water Air Soil Pollut. 168(1-4), 235-248.

Berman, T. 1974 Urea in the waters of Lake Kinneret. Limnol. Oceanogr. 19(6), 977-980.

Berman, T. 1997 Dissolved organic nitrogen utilization by an Aphanizomenon bloom in Lake Kinneret. J. Plankton Res. 19(5), 577-586

Berman, T. \& Chava, S. 1999 Algal growth on organic compounds as nitrogen sources. J. Plankton Res. 21(8), 1423-1437.

Berman, T., Bechemin, C. \& Serge, Y. M. 1999 Release of ammonium and urea from dissolved organic nitrogen in aquatic ecosystems. Aquat. Microb. Ecol. 16, 295-302.

Downing, T. G., Meyer, C., Gehringger, M. M. \& Van de Venter, M. 2005 Microcystin content of Microcystis aeruginosa is modulated by nitrogen uptake rate relative to specific growth rate or carbon fixation rate. Environ. Toxicol. 20, 257-262.

Duan, S. W. \& Bianchi, T. S. 2007 Particulate and dissolved amino acids in the lower Mississippi and Pearl Rivers (USA). Mar. Chem. 107(2), 214-229.

Flynn, K. J. \& Butler, I. I986 Nitrogen sources for the growth of marine microalgae: role of dissolved free amino acid. Mar. Ecol. Prog. Ser. 34, 281-304.

Gardner, W. S. \& Lee, G. F. 1973 Gas chromatographic procedure to analyze amino acids in lake waters. Environ. Sci. Technol. 7(8), 719-724.

Glibert, P. M. \& Terlizzi, D. E. 1999 Cooccurrence of elevated urea levels and Dinoflagellate blooms in temperate estuarine aquaculture ponds. Appl. Environ. Microbiol. 65(12), $5594-5596$.

Gors, S., Rentsch, D., Schiewer, U., Karsten, U. \& Schumann, R. 2007 Dissolved organic matter along the eutrophication gradient of the Dar $\beta$-Zingst Bodden Chain, Southern Baltic Sea: I. Chemical characterisation and composition. Mar. Chem. 104(3-4), 125-142.
Hoeger, S. J., Schmid, D., Blom, J. F., Ernst, B. \& Dietrich, D. R. 2007 Analytical and functional characterization of microcystins $\left[\mathrm{Asp}^{3}\right] \mathrm{MC}-\mathrm{RR}$ and $\left[\mathrm{Asp}^{3}, \mathrm{Dhb}^{7}\right] \mathrm{MC}-\mathrm{RR}$ : consequences for risk assessment? Environ. Sci. Technol. 41(7), 2609-2616.

Ittekkot, V. 1982 Variations of dissolved organic matter during a plankton bloom: qualitative aspects, based on sugar and amino acid analyses. Mar. Chem. 11(2), 143-158.

Ittekkot, V. 1988 Global trends in the nature of organic matter in river suspensions. Nature 332, 436-438.

Lawton, L. A. \& Edwards, C. 200I Purification of microcystins J. Chromatogr. A 912(2), 191-209.

Liu, J. K. 1999 Advanced Hydrobiology. Science Press, Beijing, China.

Lytle, C. R. \& Perdue, E. M. 198I Free, proteinaceous, and humicbound amino acids in river water containing high concentrations of aquatic humus. Environ. Sci. Technol. 15(2), 224-228.

Moollan, R. W., Rae, B. \& Verbeek, A. 1996 Some comments on the determination of microcystin toxins in water by highperformance liquid chromatography. Analyst 121, 233-238.

Orr, P. T. \& Jones, G. J. I998 Relationship between microcystin production and cell division rates in nitrogen-limited Microcystis aeruginosa cultures. Limnol. Oceanogr. 43(7), $1604-1614$

Rao, P. V. L., Bhaskar, A. S. B. \& Bhattacharya, R. 1996 Effects of nutrient media and culture duration on growth, macromolecular composition and toxicity in batch cultures of Microcystis aeruginosa. Microbios 86(347), 95-104.

Rinehart, K. L., Namikoshi, M. \& Choi, B. W. 1994 Structure and biosynthesis of toxins from blue-green algae (cyanobactria). J. Appl. Phycol. 6(2), 159-176.

Rinta-Kanto, J. M., Ouellette, A. J. A., Boyer, G. L., Twiss, M. R., Bridgeman, T. B. \& Wilhelm, S. W. 2005 Quantification of Toxic Microcystis spp. during the 2003 and 2004 blooms in Western Lake Erie using quantitative real-time PCR. Environ. Sci. Technol. 39(11), 4198-4205.

Rosa, R. \& Nunes, M. L. 2005 Seasonal patterns of nucleic acid concentrations and amino acid profiles of Parapenaeus longirostris (Crustacea, Decapoda) in relation to growth and nutritional condition. Hydrobiologia 537(1-3), 207-216.

Vezie, C., Rapala, J., Vaitomaa, J., Seitsonen, J. \& Sivonen, K. 2002 Effect of nitrogen and phosphorus on growth of toxic and nontoxic Microcystis aeruginosa strains and intracellular microcystin concentrations. Microb. Ecol. 43(4), 443-454.

Watanabe, M. F. \& Oishi, S. 1985 Effects of environmental factors on toxicity of cyanobacterium (Microcystis aeruginosa) under culture conditions. Appl. Environ. Microbiol. 49(5), $1342-1344$

Yan, H., Pan, G., Zou, H., Song, L. R. \& Zhang, M. M. 2004 Effects of nitrogen forms on the production of cyanobacterial toxin microcystin-LR by an isolated Microcystis aeruginosa J. Environ. Sci. Health A 39(11-12), 2993-3003. 